\title{
A Career in Professional Services: Accident, serendipity or something
} more?

\section{Authors}

Dr Julie-Anne Regan

Academic Development

The Leadership, Organisational, Staff \& Academic Development Academy

University of Liverpool,

126 Mt. Pleasant,

Liverpool L69 3GW

j.regan@liverpool.ac.uk ${ }^{1}$

ORCiD: 0000-0002-3516-5046

Dr Carroll Graham

Faculty of Arts and Social Sciences, University of Technology Sydney,

PO Box 123

Broadway NSW 2007

Email: carroll.graham@uts.edu.au

ORCiD: 0000-0001-6901-1048

\section{Abstract}

As part of a larger study, professional staff from two universities, Australian and British, were asked how they entered into a higher education career and what factors kept them in that career. Many participants reported that they found themselves in professional services almost by accident, or by a fortunate combination of circumstances. However, in addition to the serendipitous recruitment reported in earlier studies, our analysis found a positive value associated with higher education that attracted people to seek out employment opportunities, and to remain in the sector. This suggests that recruitment is not as accidental or serendipitous as might first appear. We argue that while there are many reasons why our participants remained in higher education, the variety offered in day-to-day roles and responsibilities is a key factor in retaining professional staff. Our findings have implications for policy and practice, for both the recruitment and retention of talented professional staff.

\section{Key Words}

Professional Staff; recruitment; staff retention.

\section{Introduction and background}

This paper explores the common phenomenon of professional staff embarking on an 'accidental career' in higher education. By that we mean that many professional staff report entering into a higher education role without prior intent, or deliberate career planning. Despite the lack of career planning, a significant number of professional staff continue to

\footnotetext{
${ }^{1}$ At the time of the research Dr Regan was affiliated to University of Chester.
} 
work in the sector for many years. This phenomenon was beautifully summed up by Gander, Moyes and Sabzalieva:

If there is one thing that binds many of those who have worked in higher education administration for some time, it's a sense of surprise that we got here in the first place, that we're still here and that this is, indeed, a place where you can build and develop a rewarding working life. (2014, p. 2)

This paper examines the factors influencing recruitment into a professional staff role and retention in that role thereafter, as well as the implications of those findings. The results from both case studies are discussed in this paper. This paper will be of particular interest to professional staff and their managers, as well as others who are concerned with higher education policy and practice.

A recent study conducted by the authors (Graham \& Regan, 2016) explored the contribution of professional staff to successful student outcomes in case studies located in Australia (Case Study 1 [CS1]) and the UK (Case Study 2 [CS2]). The method of data collection chosen to investigate this contribution was semi-structured interviews. As is the norm when conducting interviews of this nature (Jacob \& Furgerson, 2012), the researcher sought first to make the participants comfortable and establish a rapport. This was done by asking the participants to talk about how they came to work in higher education, followed by 'what keeps you here?'. When analysing the transcripts it quickly became apparent that many participants reported their entry into higher education as 'accidental' or that they 'fell into it'. Whilst this was not a major finding in response to the research questions of the original study, it was a finding we felt warranted further exploration. With professional staff making up the majority of the higher education workforce in both Australia (Department of Education and Training, 2017) and the UK (Higher Education Statistics Agency, 2017), they are both a significant resource and cost to their institutions. Like all large organisations, substantial resources have been invested into recruitment and retention across the sector (Netswera, Rankhumise, \& Mavundla, 2005). Therefore, gaining a greater understanding of what attracts and retains individuals in their current roles can inform strategies for 'attracting and retaining talented staff in higher education institutions' (Takawira, Coetzee, \& Schreuder, 2014, p. 2). In times of severe pressure on resources and greater public accountability, strategies to enhance effective recruitment and retention of staff are important to consider; not least because of the disruption to services and costs of staff turnover.

\section{Findings from previous studies}

Whitchurch (2009) concluded that despite attempts from professional organisations to 'promote university administration ... as a career' (p. 2), participants in her study 'tended towards the serendipitous' (p. 2). Summarising the serendipitous factors, Whitchurch identified six main themes, which are replicated in Box 1 below. For those participants who were in senior roles at the time of the interview, they had begun their careers at more junior levels rather than having been head-hunted for a senior role. Hence the last theme did not feature in their responses. Whitchurch, Skinner and Lauwerys (2009), reporting on a study of 40 professional staff participants, confirmed Whitchurch's earlier findings. They were also studying early career professional staff, so the first five categories were relevant. There are some potential overlaps between the first and fourth of these themes, but presumably the fourth theme relates to those with no experience of working in higher education whilst 
studying. From our initial analysis of the data, our themes appeared to resonate significantly with Whitchurch's themes (2009), and the overall perception that careers were unplanned and serendipitous in nature. However, underpinning these serendipitous or 'accidental' factors reported by participants, there seemed to be an additional attraction to working in the higher education sector. This attraction was not confined to participants who had experience of higher education as a student. Whilst this finding was not relevant to our initial study, it was an area we wished to revisit.

Box 1. Reasons for entering higher education administration (Whitchurch, 2009, p. 2-3)

1. Part-time or vacation work at their institution while a student;

2. Contact with someone who worked in a university;

3. A wish to be in a particular locality where the university was a major employer;

4. A desire to stay in an academic environment after undertaking a program of study;

5. A belief in the transferability of an individual's skills and experience from another sector, and that working in higher education would extend this experience;

6. (More senior roles) head-hunted by a vice-chancellor or senior manager.

\section{Methods}

As previously mentioned, data was collected using semi-structured interviews in two case study institutions: one in Australia and one in the UK. Fourteen participants were recruited in each case study. As such, the findings pertain specifically to those cases, but they may provide some insights into similar institutions elsewhere. Although the profile of participants was not identical in each institution, both case studies drew from a wide range of professional staff roles.

In the initial study, after the interviews had been transcribed and the transcriptions checked by participants, a software package called Dedoose $($ C (Version 6.2.17, 2015) was used as an aid to analyse the data. In the original study 'accidental career' was established as a 'parent code' with positive or negative 'child codes'. For this paper a further and more detailed analysis was conducted of the responses to the first two 'settling in questions':

- 'So how did you get into higher ed. in the first place?'

- 'So that's how you got into higher ed., now what keeps you here?'

As DiCicco-Bloom and Crabtree (2006) pointed out, the researcher has comparatively little time to establish a rapport with their interviewees, so care is needed in phrasing the initial questions. The purpose is to encourage the interviewee to relax and speak freely, so the initial topics should be 'broad and open-ended' but at the same time 'should reflect the nature of the research and be non-threatening' (DiCicco-Bloom and Crabtree, 2006, p. 316). The questions we posed fulfilled these criteria and elicited richer responses than we had expected for 'settling in questions'. Jacob and Furgerson $(2012$, p. 4) recommend the phrase 'Tell me about' to encourage the interviewee to begin a narrative and which even 'subtlety [sic] commands the interviewee to begin talking'. We consider that our opening questions fulfilled the same purpose, and judging by the expansive responses, they achieved that effectively. 
In analysing this data in more depth we sought to answer the following research questions:

1. What factors do participants report as contributing to their entry into higher education professional staff roles?

2. Do these factors have possible implications for recruitment of professional staff?

3. What factors do participants report as contributing to them pursuing their career in higher education?

4. Do these factors have possible implications for development and retention of professional staff?

5. To what extent do the responses from both case studies reflect similarities or differences?

Version 7.6.6 of Dedoose C (2017) was used to assist in the analysis of the data. The interview transcripts were coded to indicate all the factors identified in the responses to those two questions posed at the start of each interview. Each transcript was analysed and coded, with a new code being created whenever a new factor was identified.

\section{Limitations}

As with any qualitative research the sample size of this comparative study is relatively small, comprising a total of 28 participants from two institutions. Furthermore, consistent with research ethics, participants in this study were self-selecting, as they needed to respond to a request to participate in the study and be willing to give 60 to 90 minutes of their time to be interviewed. Thus it could be assumed that participants in our two cases would be motivated and successful in their careers in higher education, and hence might present a more positive picture than that discovered by a random sample of professional staff.

In addition, as the findings in this paper arose from 'settling in questions', only issues regarding the main theme of the study (their contribution to student outcomes) were explored more deeply during the interviews. Thus some issues now identified in further analysis of these 'settling in questions' will now become topics for future research.

Notwithstanding these limitations, qualitative data provide a rich, thick description of actions that embody intentions and meanings, thus allowing the development of a holistic perspective that can reveal complexities (Miles \& Huberman, 1994). Moreover, this study is congruent with appreciative inquiry, in which research seeks to determine the strengths necessary for 'designing, transforming, and growing effective organizations' (Cooperrider, Whitney, \& Stavros, 2008, p. vii). Thus this study provides the opportunity to focus on how other institutions might foster recruitment and retention of their professional staff, for the benefit of the staff, their academic colleagues, students and the institutions themselves.

\section{Results and discussion}

Although we found some overlapping themes between what factors contributed to 'getting into' higher education and those that contributed to professional staff remaining there, we have decided to present the results separately to address our research questions more closely. The most strongly overlapping theme is what we termed 'A positive environment'. This code was applied whenever participants cited the positive higher education environment as a reason for either starting their career or for encouraging them to pursue it. 


\section{Entry into higher education roles}

\section{Higher education as a positive environment: a nice place to work}

From an entry perspective the 'positive environment' code was applied when participants cited their perception of higher education as an inherent 'good', leading them to apply for a position. This did not exclude them from reporting having 'fallen into it' but, having found themselves in a position to start employment in higher education, the nature of the sector as an entity was seen to have positive value. Whilst participants may have just happened to see an opportunity, it was often qualified with expressions of the value they placed on what kind of 'business' goes on in a university. Participants did not always make a direct link between entering a higher education career, and the value they placed on universities, being places of work that were contributing to society in a valuable and positive way. The serendipitous entry, as described by Whitchurch (2009), is often first mentioned in responses, but participants would then further reflect on their value perceptions of higher education as an employer, as illustrated by the quotes in Box 2. In other words, part of the reason why they even noticed jobs being advertised was because inherently they believed universities would be nice places to work at, due to the nature of their business.

Education is associated with doing good, making a difference, performing an important role, and therefore would be a positive environment in which to seek employment. For some participants, education being a 'public good' fitted well with their personal values, offering a more altruistic alternative to the perceived profit focus of the corporate world. Although the term 'public good' is ill defined and ambiguous, we are using it here to mean something that has inherent value to the public: open, transparent and a general benefit. According to Marginson (2011) the term 'public good' is commonly associated with higher education and is often viewed as 'the opposite of an unregulated capitalist market' (p. 418). For many participants this concept of higher education was an attractive incentive for recruitment. Although the word 'nice' is intrinsically imprecise, we have used that term deliberately in this theme, as it was used so often by participants.

Box 2. Participant views on the inherent value of working in higher education from both Case Study sites

At the same time I feel that it's not commercial, although I know that there is a business side to universities in terms of students I feel like I'm contributing to something worthwhile rather than a money making enterprise that I wouldn't necessarily feel comfortable with. (CS1)

I also like the environment. It's a creative environment, it's an interesting environment, you're often working with some very bright people with some interesting ideas. It's - generally I've found them to be supportive environments as well and it hasn't been about purely the pounds and the pence, you know, I've always - I want to work somewhere that has a supportive ethos for people. (CS2)

And it sort of reminded me how much I enjoyed my university and it made me think I would like to get back into a university environment. (CS1)

I really like the fact that you're working a place of learning. And universities are very institutionalised, but that's, it's quite nice. It's like a bubble, I suppose. And you kind of feel like everybody's working towards a common purpose. (CS2)

Also a lot of people who are passionate about topics and I find them really engaging and interesting ... and also the nature of the activity that goes on around here. (CS1) 
It's not like some cut-throat private enterprise where profit is king and if you don't achieve your targets every week you're out. (CS2)

I like being around all the learning and enthusiasm and that sort of thing. (CS1)

And I was looking for something that I felt fit my values. (CS2)

University in my opinion, apart from the invaluable facilities that are available to educate youngsters, or not so young people, I believe offers a far more extensive service to the greater community and I believe that should be supported. (CS1)

I was very happy to work in the university because it's kind of the background that I grew up in. (CS2)

\section{Good match with transferrable skills}

This was an important factor cited as attracting participants to the particular role they applied for, as an early career member of professional staff. Often these transferrable skills were 'people skills', with customer service being mentioned as a transferrable background.

In terms of that, looking for the next role, I was thinking, well I really like working with people, I like to see development, I like to see change, but I didn’t necessarily want to stay with ... (CS2)

This kind of gave me an opportunity to, I guess, again deal with people from different backgrounds and that sort of service element was there, and opportunities for training and developing new skills that just seemed like an area that I'd be a perfect fit for. (CS1)

With a growing emphasis on articulating 'key skills', 'graduate skills' and 'employability skills' (a plethora of terms exist) to students in higher education, it will be even more apparent that, whatever the topic studied at university, they have also developed other skills suited to administrative roles across many sectors.

Interestingly, the quotes above were from one male and one female participant but the perception of professional staff roles involving 'working with people' may be worth exploring in terms of the gender bias seen in the current workforce. Holland's Hexagon (1975) of vocational interests is underpinned by 'two theory-based dimensions - data/ideas and things/people' (Prediger, 1982, p. 259). Although this model may have its critics (Tinsley, 2000), the dimensions are interesting to contemplate in relation to professional staff roles. There is reasonable consensus that in very general terms, males are more attracted to vocations characterised by data and things, whereas females are more attracted to vocations characterised by ideas and people (Rhoten \& Pfirman, 2007). Because professional staff roles are so diverse, and yet are often discussed as a generic entity (Graham, 2010), the subtleties may not be apparent, and thus career options may be discounted. If applicants assume working in higher education is synonymous with 'working with people' (CS1) they may be dissatisfied with some roles they could find themselves in, or alternatively, overlook it as a career option. Whilst our samples are too small to draw any firm conclusions, roles with 'technology' in the title may be more attractive to males than those with 'administration' or 'student support'. This is an area worth further exploration, especially in the UK, where there is the possible introduction of a 'Degree Apprenticeship' for higher education Administrators.

\section{Fell into it}


Initially the number of times participants actually used the terms 'fell into it' or 'by accident' surprised the first author who did not have a background in professional services. These terms were more frequently used in CS2 than CS1, which may indicate a subtle difference in culture and/or language use. Whereas Whitchurch (2009) talks of serendipitous factors, the notion of 'falling into it' or arriving 'by accident' sounded more negative. It was easy to imagine that the 'accident' or 'fall' could result in a poor outcome for employee and employer alike. On closer analysis, the notion of an accidental career did indeed seem to be more like a serendipitous collection of factors that led people to start a career in higher education. In addition to the positive perception of the sector as a whole, conditions of employment were also viewed as attractive.

Basically, I fell into it. (CS1)

I saw the job advertised in the local paper in those days and I thought, 'Well, that looks interesting,' not necessarily with a longer term career aim at that point but it was a permanent job, it was stability, wasn't the best paid but I thought, 'Let's go for it and see how we get on'. (CS2)

The answer is - a lot of support staff will probably give you the same answer - in that you kind of just fall into it. (CS2)

\section{Geographical location}

The geographical location of each case study institution was a significant draw for participants, in terms of recruitment as well as retention. The case study institutions were in very different types of cities but both were city campuses. CS1 was in a large capital city, whereas CS2 was in a small provincial city renowned for its historical appeal. For CS1, the geographical 'pull' was often the specific location of the university within the city, whereas for CS2 it was more related to the general county area. The county is viewed as a 'nice place to live', and travelling into the city itself is relatively easy. However, CS2 had been altering its structure by taking on new campuses outside the area, and thus may need to monitor the impact of the changes on recruitment, both for students and staff.

I've always wanted to get jobs closer to the university so I don't have to commute as far [to study there] and eventually I got a job at the university. (CS1)

I'm from that area as well, you see. So it was ideal from that point of view. That's how I first got it. (CS2)

\section{Family member or contact}

This was cited as a contributing factor to recruitment more frequently by participants from CS1 than those in CS2. However, personal knowledge of CS2 indicates this is an important factor to consider for that institution too, albeit not for the participants in this study. Whitchurch (2008), confirmed later by Whitchurch and her colleagues (2009), found that 'contact with someone who worked in a university' (p. 2) was a factor, but this was particularly a family member in our data. This finding could be seen as reinforcement that higher education is viewed as a positive employment opportunity, as presumably family members would provide an in-depth insight into working in the sector. It might be more likely for family members to be seen as having shared values or being of a 'like-mind'. There are also practical considerations of such things as shared travelling which might be attractive to employees from the same family.

When I came back [from overseas] I was uncertain about what I wanted to do and my son was working here. (CS1) 
Well, partly because my partner at that time was a student here. (CS2)

\title{
Remaining in higher education
}

\section{Higher education as a positive environment: A 'nice place to work'}

Higher education as a 'nice place to work' was not only cited as an attraction to working in the sector, but also as a reason for remaining; in fact, it was by far the most frequently cited reason for retention.

And if I was to leave, I would be very hesitant and reluctant because I value academia. (CS2)

Within the broader theme of being a 'nice place to work' discussed above, fellow workers and their values were frequently cited reasons for remaining in higher education. Colleagues were considered to be 'like-minded' and to treat each other with respect and politeness.

\begin{abstract}
Also a lot of people who are passionate about topics and I find them really engaging and interesting. I think it's the flexibility and also the nature of the activity that goes on around here. (CS1)
\end{abstract}

We've got the wider environment in terms of the university being very community focused and you've also got the department and the team you work in, very lucky. Yes, we all have the odd day where we squabble, but generally speaking very supportive and focused on teamwork, which is a great place to be. Why throw that away when you're getting staff development opportunities, when you're progressing, when you're getting new experiences and you've got a supportive team? (CS2)

In that way, higher education as a workplace was seen as a safe place to be. Because we were not exploring this issue in depth at the time, participants were not asked what factors they felt contributed to such a collegial atmosphere, but it was a key factor in retaining these experienced staff. As commercial pressures continue to increase in the higher education sector, it is important to ensure that the culture of collegiality and mutual respect is not lost. Although such a culture may have arisen from the privileged and exclusive history of higher education, it seems to have so far endured the impact of massification, commercialisation and, in some cases, ongoing upheaval and re-structuring.

Although many participants had been in their jobs for a number of years, job security was only cited by one participant as a positive factor in retention. Several participants did indicate that they had remained because they were unsure of gaining other meaningful employment elsewhere. Although this attitude might be viewed negatively, it was also associated with higher education offering a 'nice place to work' and friendly colleagues. In other words, they perceived that a factor influencing their retention was that they were unsure such favourable working conditions could be found elsewhere.

I love not being the smartest person around the place. That sounds really arrogant, doesn't it? In the organisations that I worked in before, there weren't many people that were more clued up about what I do than me. I was very much working alone. It was difficult to find people who were as engaged and familiar with the areas I was working in as me. (CS1) 
Participants who had worked in the commercial sector reported that such a culture of mutual respect was not always apparent in their previous employment and it was viewed as a reason not to venture to, or return to, that sector.

The work life balance and the benefits of working here are a great deal nicer than working in the private sector...certainly the way that you are treated and spoken to ... I do find quite a lot of people are still here because they're scared to move on in the private sector. (CS2)

\section{Varied nature of the work}

Another frequently cited reason for job satisfaction and retention was the varied nature of people's roles in higher education. There were examples of when the nature of the role meant each day was very different, even though there were cyclical patterns over the academic year.

Every day is different, even though I've been here nearly four years; I've only experienced some of the same things three times. (CS 2)

There were other examples of how roles evolved over time as new initiatives or policies were introduced.

So there's been a lot of change since I started. If it wasn't for those factors I might have moved on because I might have got a bit bored. (CS1)

Such variations in their roles were viewed quite positively by participants, for maintaining their interest and keeping their roles fresh. However, it did mean that some participants reported their job descriptions bore little resemblance to the actual work being undertaken, a phenomenon that may be referred to as 'job discrepancy' (Khalid \& Naeem, 2013). In contrast to other studies (Khalid \& Naeem, 2013; Barbouletos, 2011), when job discrepancy was reported in our study this was without any resentment and often with humour. By implication this could have an impact on the grading or remuneration for such roles and, in time, subsequent recruitment. Because the varied nature of professional staff roles is such a motivational force in retention, the sector must guard against any risk of exploitation. Capable professional staff take on new activities, which add interest to their daily work; however, they may find themselves inadequately rewarded for the increased level of responsibility resulting from their enthusiastic response to change and development. While outside the scope of this study, there is potential for future research to unpack this issue.

Finally there were examples of participants changing roles and even departments during their time at the institution.

So, you can imagine that journey, over the 15 years has been really quite exciting in terms of the work that I've been doing. Within that time period, I've also had three different job roles. (CS2)

Mobility between professional service departments, or roles within the institution, was considered a positive factor in the retention of some participants. It preserved the benefits of a familiar workplace, whilst offering new challenges and stimulation. Supporting such movements within the institution has significant institutional benefits, fostering the development of what Demirkan and Spohrer (2015) refer to as 'T-shaped' professionals, who are adept at collaborating across the institution with concomitant benefits for service delivery. 


\section{Making a difference with their personal contribution}

As previously mentioned, many participants considered (higher) education being of inherent value. Despite recent challenges to the role of higher education as a 'public good' (Kezar, Chambers, \& Burkhardt, 2015), participants in our study viewed the essence or purpose of higher education as a 'public good' - to improve and develop people who, in turn, would better society. This was a factor favouring recruitment, and it was also a reason for remaining. Participants expressed a degree of pride to be part of an entity with such a laudable purpose. More importantly, many participants acknowledged their part in making a difference, both generally as part of this inherent good, as well as to individuals who were experiencing higher education. Higher education was viewed as a working environment in which individuals could make a positive contribution to others, particularly to young people.

What I love is that the work you do in universities just has such profound impact for the rest of their life. (CS1)

I like working in an area where I feel I can make a difference to people and I feel that universities are a place where you can do that. (CS2)

'Making a difference' appeared to have a sustainable impact on retention because participants could see evidence of when their contribution had enhanced the experience of students, even indirectly. That reinforced the belief that working in the higher education sector enabled them personally to 'make a difference'.

I do really enjoy that role of supporting students in their studies; it's quite a fulfilling sort of feeling. (CS1)

And you kind of have a feel - of self-worth, the fact that you're working somewhere that's benefiting other people. So, you know, the same way that somebody might work for a charity might have the same sort of feeling. Even though you're a tiny, tiny cog in a massive wheel, it has some benefit to the wider society because students are here to learn, and all that kind of stuff. (CS2)

\section{Developmental opportunities}

Many participants spoke of the development opportunities afforded by the institution as a motivating factor for retention. For some participants this was related to gaining higher degrees. This was particularly, but not exclusively, noted in CS2, where fees were waived and study time permitted if the study could be linked to the job role. The opportunities to learn seemed consistent with the educational purpose of the institution, and certainly contributed to retention in both of these two case study sites.

I started as the office co-ordinator and I finished my degree and then I did a Masters. (CS1)

The director at that time suggested, 'Well, what career development are you going to do? What Master's, what further qualifications?' (CS2)

Although there might be an impression that some professional staff view their roles as a stepping stone to academia, this was only reported by one participant in CS2 and none in CS1. Even for that participant it was not the only factor that motivated them to continue in higher education. 


\section{Self-determination theory and retention of professional staff}

The prevalent themes, discussed above, appear to satisfy what are known as 'universal necessities' in self-determination theory (SDT) of work motivation (Gagné \& Deci, 2005, p. 337). These necessities are autonomy, competence and relatedness and, according to Gagné and Deci (2005), jobs that 'promote satisfaction of the three basic psychological needs will enhance employees' intrinsic motivation and promote full internalization of extrinsic motivation' (p. 337). Not only does this lead to increased job satisfaction and performance-related benefits, but Reis and his colleagues (2000) demonstrated a direct link between the daily experiencing of these factors, and measurable contributions to well-being indices. More recently, SDT has been used as a framework of analysis for the well-being of academics (Fein, Ganguly, Banhazi, \& Danaher, 2017). Clearly, satisfying the needs of SDT is a 'win-win' situation for employer and employee.

In Figure 1 we represent our findings on the reasons that participants continue their employment in higher education, which can be viewed as factors that promote the three essential components of SDT.

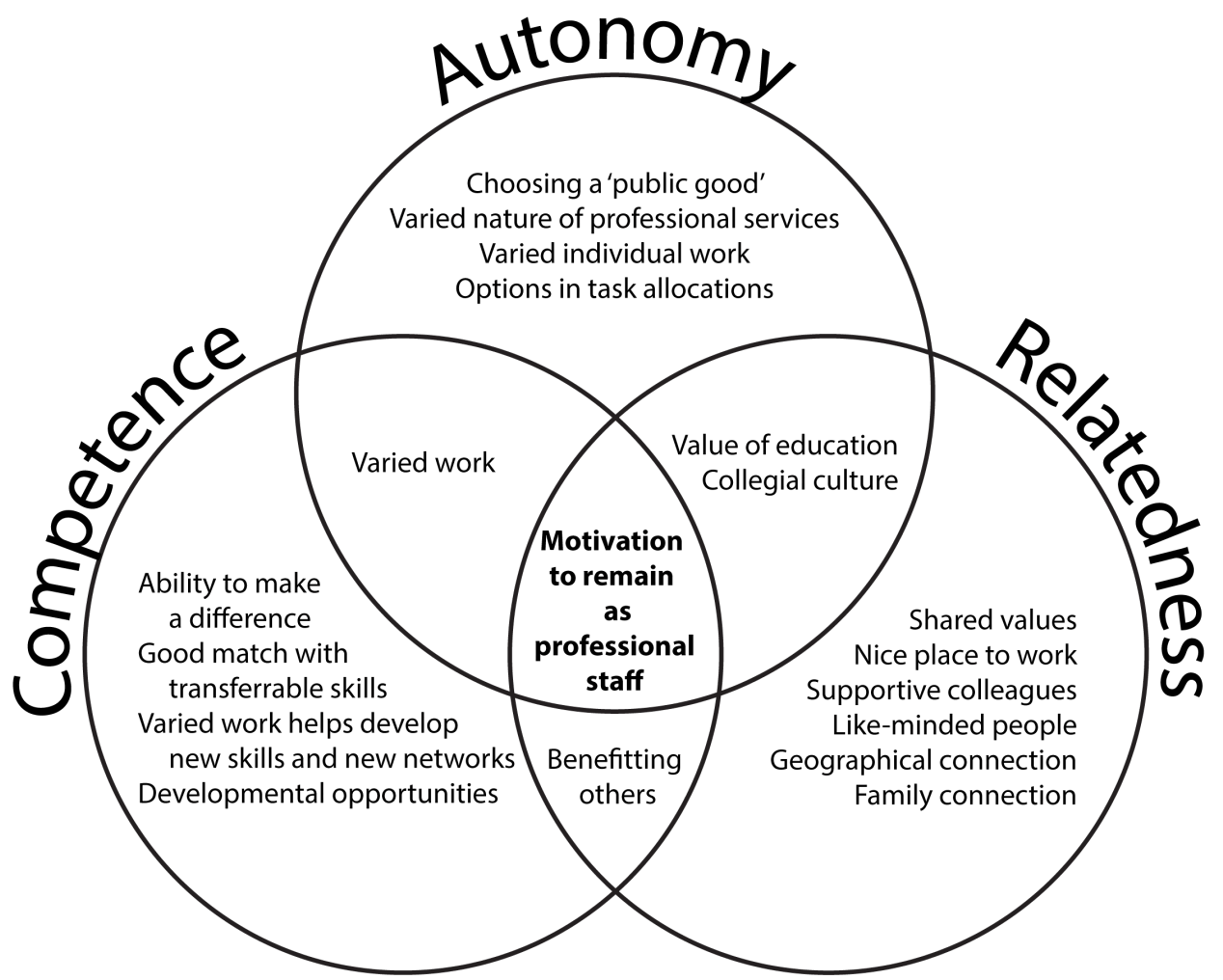

Figure 1. Factors promoting the universal necessities of the self-determination theory and retention of professional staff in higher education.

According to Gagné and Deci (2005, p. 333), 'Autonomy involves acting with a sense of volition and having the experience of choice'. Competence and relatedness may well lead to feelings of job satisfaction but this can only be truly internalised if individuals 'inwardly grasp its meaning and worth' (Ryan \& Deci, 2000, p. 64). In our findings, factors identified as promoting autonomy can be summarised as the intrinsic value of higher education, the varied and evolving nature of the roles, and the collegial (and polite) culture that leads to options in task allocations. Understanding and grasping the value of ones contribution to the perceived 'public good' of higher education, is motivational and promotes feelings of selfworth. Although perhaps the varied nature of the work is not always voluntary, there was a sense of choice and self-determination about taking on new roles and varied projects. This 
feeling may be enhanced by the way in which participants report being treated by colleagues: being asked politely to take on something new being more effective in promoting autonomy than being directed to do so.

With regards to competence as a need, Ryan and Deci (2000) recognise that an individual needs to 'feel efficacious' (p. 64) about undertaking their role, in order to feel motivated to carry it out. In our study participants point to several factors which would support their need to feel competent: the provision of developmental opportunities; varied work helping to develop new skills and networks; making a difference to others; and again that collegial culture, which is supportive and values learning. Although in many institutions conditions of work in relation to ongoing professional development favour academic staff over professional staff (Graham, 2009), participants still reported these opportunities as an important factor in motivating them to remain in their roles. Participants found that because their roles were so varied, with lots of opportunities to participate in different initiatives and projects, their skill set had become extensive and they had created a lot of useful networks across the institution. Because all the participants had significant experience in higher education professional staff roles, competence could be over-represented in our case studies. However, creating environments that promote retention of staff will increase the likelihood of building a competent workforce. Making a positive difference to students, both in terms of their experience and their outcomes, is evidence of staff competence. Such evidence provides feedback to professional staff of their competence, further satisfying their 'basic psychological need' (Gagné \& Deci, 2005, p. 337).

In SDT the term 'relatedness' is defined as 'a sense of belongingness and connectedness to the persons, group, or culture disseminating a goal' (Ryan \& Deci, 2000, p. 64), All our findings relating to higher education being a positive environment in which to be employed - a nice place to work - support this third underlying factor of SDT. There is clear evidence that people are attracted to, and remain in, professional staff roles because they feel a connectedness to the place, the people, and the purpose of the institution. As reported earlier, participants often cited the shared values and 'like-mindedness' of their colleagues as reasons for remaining in higher education.

There is clear evidence in our results that the three underpinning requirements of SDT are present in the responses of our participants. This not only helps to analyse the findings of our sample, but also provides a framework for promoting work motivation, job satisfaction, performance-related benefits and, ultimately, retention of these motivated employees. Furthermore, when the three basic psychological needs described by SDT are met, there is a greater capacity for contributing to the success of others (Fein et al., 2017). This was demonstrated in relation to students, as well as professional and academic colleagues, in the two cases studied.

\section{Conclusions and recommendations}

From our brief and serendipitous exploration of this topic, it seems clear that careers in professional staff roles, within higher education, are not quite as accidental as may first appear. All factors relevant to early career professional staff that Whitchurch (2009) found in her study (Box 1) were present in our sample. But there is an important, additional factor to consider - the inherent value associated with the purpose of higher education. 
The above finding is not only important to initial entry into higher education professional staff roles, but also to retaining individuals in those roles. Many participants pointed to the fact that they were able to 'make a difference' as being a key motivator for retention. The opportunity to make a real difference to the experience and the outcomes of students is a contribution not always made explicit (Graham \& Regan, 2016).

The other major factor, which has implications for retention in particular, is the varied nature of the work cited by so many of our participants. Thus, work should be organised in such a way as to maintain variety for professional staff, to avoid narrowing of work roles. From a recruitment perspective this may not be a typical perception of professional service roles, which may be imagined as routine and standardised. We have concluded that research into young peoples' perceptions of careers as professional staff is much needed, and will be valuable in raising the profile of such career opportunities. Linked with this more general understanding of perceptions is the gender issue where, in common with other female dominated professions, there is scope for action.

We have argued that many of the reasons reported for 'still being here', can be related to self-determination theory (Gagné \& Deci, 2005), providing significant motivation to continue working in the sector. Identifying the factors that support the three basic requirements for intrinsic motivation provides useful information for recruitment and retention.

The opportunities for formal development were a particular feature of CS2, with more participants there having higher degrees than those at CS1 (Graham \& Regan, 2016). However, personal and professional development was not confined to formal qualifications, and such development was viewed as a positive aspect of remaining in the sector. Alongside the opportunities for varied work came the opportunities to learn new skills and meet new colleagues. This provides greater networking opportunities which can be valuable for 'getting things done' when normal processes and procedures are cumbersome and slow to react.

Finally, the comparative aspect found the two case studies were so closely aligned that it is hard to imagine there is such a large geographical distance between them. The cities were very different and the campuses set up in very different ways. Nevertheless, the experience of working in the higher education sector as professional staff was remarkably similar, and the sector itself seems to have some distinct features. It is our view that these distinct features are not yet fully exploited in the recruitment and retention policies and practices, and to exploit them more effectively could offer significant benefits for the sector.

\section{References}

Barbouletos, S. (2011). Discrepancy between role expectations and job descriptions: the impact on stress and job satisfaction. (Master's thesis). Retrieved from http://hdl.handle.net/1773/17087

Cooperrider, D., Whitney, D.D., \& Stavros, J.M. (2008). The appreciative inquiry handbook: For leaders of change. San Francisco, CA: Berrett-Koehler Publishers.

Dedoose Version 6.2.17 [Web application for managing, analyzing, and presenting qualitative and mixed method research data]. (2015). Retrieved from http://www.dedoose.com

Dedoose Version 7.6.6 [Web application for managing, analyzing, and presenting qualitative and mixed method research data]. (2017). Retrieved from http://www.dedoose.com 
Demirkan, H., \& Spohrer, J. (2015). T-shaped innovators: Identifying the right talent to support service innovation. Research-Technology Management, 58(5), 12-15. http://dx.doi.org/10.5437/08956308X5805007

Department of Education and Training (2017). Higher education statistics: staff data. Retrieved from https://www.education.gov.au/staff-data

Dicicco-Bloom, B., \& Crabtree, B.F. (2006). The qualitative research interview. Medical Education, 40(4), 314-321. doi:0.1111/j.1365-2929.2006.02418.x

Fein E.C., Ganguly R., Banhazi T., \& Danaher P.A. (2017) Self-Determination Theory and Academic Life. In: Riddle S., Harmes M.K., Danaher P.A. (Eds.), Producing Pleasure in the Contemporary University (pp. 171-184). Bold Visions in Educational Research. Rotterdam: SensePublishers.

Gagné, M., \& Deci L.E. (2005). Self-determination theory and work motivation. Journal of Organisational Behaviour, 26, 331-362. doi:10.1002/job.332

Gander, M., Moyes, H., \& Sabzalieva, E. (2014). Managing Your Career in Higher Education Administration. Basingstoke: Palgrave Macmillan.

Graham, C. (2009). Investing in early career general staff. Journal of Higher Education Policy and Management, 31(2), 175-183. http://dx.doi.org/10.1080/13600800902825868

Graham, C. (2010). Hearing the voices of general staff: A Delphi study of the contributions of general staff to student outcomes. Journal of Higher Education Policy and Management, 32(3), 213-223. http://dx.doi.org/10.1080/13600801003743315

Graham, C., \& Regan J.A. (2016). Exploring the contribution of professional staff to student outcomes: a comparative study of Australian and UK case studies. Journal of Higher Education Policy and Management, 38(6), 595-609. doi:10.1080/1360080X.2016.1211935

Higher Education Statistics Agency (2017). Staff. Retrieved from https://www.hesa.ac.uk/data-and-analysis/staff

Holland, J.L. (1975). Manual for the Vocational Preference Inventory. Palo Alto, CA: Consulting Psychologists Press.

Jacob, S.A. \& Furgerson, S.P. (2012). Writing Interview Protocols and Conducting Interviews: Tips for Students New to the Field of Qualitative Research. The Qualitative Report, 17(42), 1-10. Retrieved from http://nsuworks.nova.edu/tqr/vol17/iss42/3

Kezar, A., Chambers, A. C., \& Burkhardt, J. C. (Eds.). (2015). Higher education for the public good: Emerging voices from a national movement. San Francisco, CA: John Wiley \& Sons.

Khalid, M. \& Naeem, H. (2013). The Impact of Job Description on Burnout with Mediating Effect of Psychological Strain: An Empirical Evidence from the Cement Industry of Pakistan. Middle-East Journal of Scientific Research, 13(3), 288-295. doi: 10.5829/idosi.mejsr.2013.13.3.1704

Marginson, S. (2011). Higher education and public good. Higher Education Quarterly, 65(4), 411-443. doi:10.1111/j.1468-2273.2011.00496.x

Miles, M. B., \& Huberman, A. M. (1994). Qualitative data analysis: an expanded sourcebook (2nd ed.). Thousand Oaks, CA: Sage Publications.

Netswera, F.G., Rankhumise, E.M., \& Mavundla, T.R. (2005). Employee retention factors for South African higher education institutions: A case study. SA Journal of Human Resource Management, 3(2), 36-40. doi:10.4102/sajhrm.v3i2.64 
Prediger, D.J. (1992). Dimensions underlying Holland's hexagon: Missing link between interests and occupations? Journal of Vocational Behavior, 21(3), 259-287. doi:10.1016/0001-8791(82)90036-7

Reis, H.T., Sheldon, K.M., Gable, S.L., Roscoe, J., \& Ryan, R.M. (2000). Daily well-being: the role of autonomy, competence, and relatedness. Personality and Social Psychology Bulletin, 26, 419-435. doi:10.1177/0146167200266002

Rhoten, D., \& Pfirman, S. (2007). Women in interdisciplinary science: Exploring preferences and consequences. Research policy, 36(1), 56-75.

Ryan, R.M., \& Deci, E.L. (2000). Intrinsic and Extrinsic Motivations: Classic Definitions and New Directions. Contemporary Educational Psychology, 25, 54-67. doi:10.1006/ceps.1999.1020

Takawira, N., Coetzee, M., \& Schreuder, D. (2014). Job embeddedness, work engagement and turnover intention of staff in a higher education institution: An exploratory study. $S A$ Journal of Human resource and Management, 12(1), Art. \#524, 10 pages. doi:10.4102/sajhrm.v12i1.524

Tinsley, H. E. (2000). The congruence myth: An analysis of the efficacy of the personenvironment fit model. Journal of Vocational Behavior, 56(2), 147-179.

Whitchurch, C. (2008). Professional managers in UK higher education: preparing for complex futures. Final Report. London: Leadership Foundation for Higher Education. Retrieved from https://www.lfhe.ac.uk/en/research-resources/index.cfm

Whitchurch, C. (2009). Progressing professional careers in UK higher education. Perspectives: Policy and Practice in Higher Education, 13(1), 3-10. doi:10.1080/13603100802596983

Whitchurch, C., Skinner, M., \& Lauwerys, J. (2009). Recent developments in relation to professional staff in UK higher education. Australian Universities' Review, 51(1), 56-60. 